\title{
Application of the DLT Method to Anthropometry
}

\author{
Komei HATTORI \\ Laboratory of Anatomy and Physical Activity Sciences, \\ College of General Education, Ibaraki University
}

\begin{abstract}
The direct linear transformation (DLT) method was applied as a tool in the field of anthropometry. Using four video cameras which are arranged surrounding the subjects, we attempted to detect the reference points in the trunk of body and produce three dimensional coordinates of the points by the DLT method. The average error associated with the $\mathrm{x}, \mathrm{y}$, and $\mathrm{z}$ coordinates was less than $1 \%$. After getting the three dimensional coordinates of reference points, the various linear and angular dimensions were calculated.
\end{abstract}

Keywords Anthropometry, Photogrammetry, Direct linear transformation

\section{Introduction}

The measurement of three dimensional shape is becoming increasingly important to biological anthropology and the human engineering fields. The moiré topography method, one of the three dimensional analytical procedures has been applied in many studies of posture (ASHIZAWA et al., 1985; HATTORI and NISHIO, 1982). The moiré method is inexpensive and accurate, but the moiré image shows only one side of body because the light projection from a specific point is essential in this method.

The direct linear transformation (DLT) method of stereophotogrammetry was developed by ABDEL-AZIZ and KARARA (1971) and its applicability to research on human movement has been ascertained (SHAPIRO, 1978). Since this method does not require the special devices except the ordinary photogrammetric system, it is suit- able for detecting whole body surface information when we arrange several cameras around a subject. Other merits of the DLT method as an anthropometrical tool is that it is non-invasive and requires very short testing time for subjects.

In this paper, we attempted to detect the three dimensional coordinates of various anthropometrical landmarks by the DLT method.

\section{Method}

The theoretical basis for the DLT method has been described in detail (SHAPIRO, 1978; WALTON, 1979; HATZE, 1988). The four video cameras (National WV-046) were arranged surrounding the subject as shown in Fig. 1. The images from four cameras were monitored as four split images onto one video monitor (National WJ-400) for recording.

At first, a series of standardized control points are placed at the four corners of a one meter 


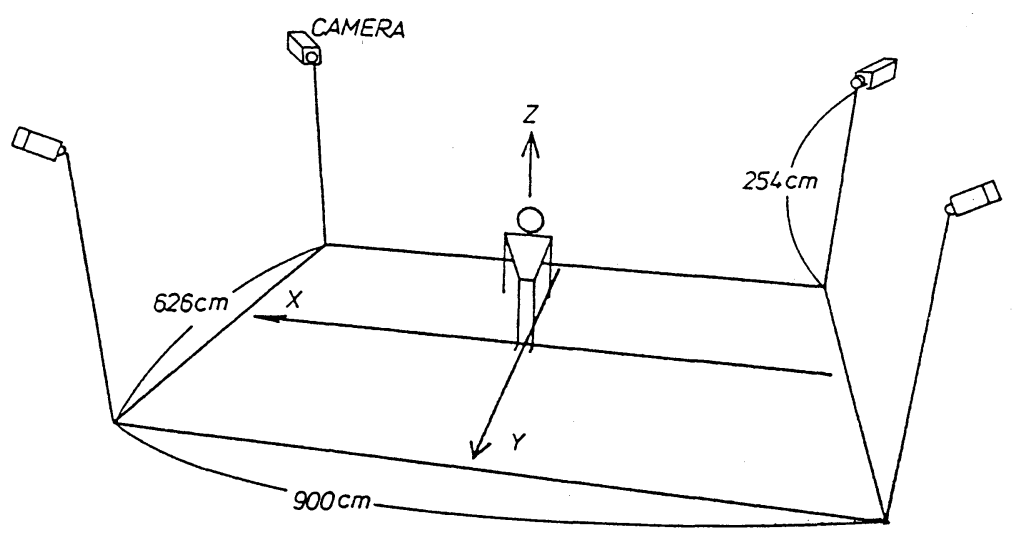

Fig. 1. Spatial arrangement of four cameras.

square field of view. Each of the control points is recorded in sequence by each of the four cameras.

Before video recording of the subjects, thirteen landmarks were put on the anthropometric points of the trunk of subjects. These are suprasternale [sst], mesosternale [mst], xiphiale [xy], right iliocristale [ic], right iliospinale [is], right acromiale [ac], midlateral point of thorax [Trx], subscapular point [Scp], cervicale [c], spinous process of $\mathrm{T} 4$ [T4], spinous process of T8 [T8], spinous process of T12 [T12] and JACOBY point $[\mathrm{J}]$. Subjects are required to take a normal standing position in the field of view and then to abduct the upper limbs to show the landmarks on the side of trunk.

The $\mathrm{x}$ and $\mathrm{y}$ coordinates were obtained by video image analyzer (superimposed system on personal computer). Three dimensional coordinates for the landmarks on the subjects were calculated by applying the DLT equations which was derived by analysis of the control point coordinates.

Since one of the four combinations by two adjacent cameras could detect all landmarks, the three dimensional coordinates of the points on the whole body could be determined.
Subjects were 74 male students ranging in age from 18 to 21 years. They were all in good health.

\section{Results}

Initially, DLT equations were solved by substituting the coordinates of the control points and deriving the DLT parameters. Since the cameras were fixed throughout the recording, these parameters were applied in all subsequent solutions.

Table 1 shows the given and calculated spatial coordinates of the control points. The average errors associated with the $\mathrm{x}, \mathrm{y}$, and $\mathrm{z}$ coordinates were $0.14 \mathrm{~cm}, 0.21 \mathrm{~cm}$, and $0.27 \mathrm{~cm}$, respectively. The error in this estimate was less than $1 \%$.

Table 2 shows the means and standard deviations of three dimensional coordinates of anthropometric points when the JACOBY point was taken as the original point. These coordinates were projected onto the horizontal (Fig. 2), frontal (Fig. 3) and sagittal (Fig. 4) planes. The several diameters between two reference points and angles formed by the three reference points are indicated in Tables 3 and 4.

\section{Discussion}

As shown in Table 1, the DLT method is 
Table 1. Results of simple static variation of the generalized three-dimensional model

\begin{tabular}{|c|c|c|c|c|c|c|c|c|c|}
\hline & \multicolumn{3}{|c|}{$\begin{array}{l}\text { Given Spacial } \\
\text { Coordinates }\end{array}$} & \multicolumn{3}{|c|}{$\begin{array}{l}\text { Computed Spacial } \\
\text { Coordinates }\end{array}$} & \multicolumn{3}{|c|}{ Absolute Error } \\
\hline & $\mathrm{X}$ & $\mathrm{Y}$ & $\mathrm{Z}$ & $\mathrm{X}$ & $\mathrm{Y}$ & $\mathrm{Z}$ & $\mathrm{X}$ & $\mathbf{Y}$ & $\mathrm{Z}$ \\
\hline 1 & 30.4 & 30.4 & 20.0 & 30.51 & 30.50 & 20.19 & 0.11 & 0.10 & 0.01 \\
\hline 2 & 30.4 & 30.4 & 40.0 & 30.11 & 30.55 & 39.74 & 0.29 & 0.15 & 0.26 \\
\hline 3 & 30.4 & 30.4 & 60.0 & 30.35 & 30.24 & 59.61 & 0.05 & 0.16 & 0.39 \\
\hline 4 & 30.4 & 30.4 & 80.0 & 30.30 & 30.23 & 80.46 & 0.10 & 0.17 & 0.46 \\
\hline 5 & 30.4 & 30.4 & 100.0 & 30.43 & 30.17 & 100.33 & 0.03 & 0.23 & 0.33 \\
\hline 6 & 30.4 & 30.4 & 120.0 & 30.45 & 30.81 & 119.49 & 0.05 & 0.41 & 0.51 \\
\hline 7 & 30.4 & 30.4 & 140.0 & 30.57 & 30.19 & 139.95 & 0.17 & 0.21 & 0.05 \\
\hline 8 & 30.4 & 30.4 & 160.0 & 30.23 & 30.11 & 160.37 & 0.17 & 0.29 & 0.37 \\
\hline \multirow[t]{2}{*}{9} & 30.4 & 30.4 & 180.0 & 30.10 & 30.61 & 180.03 & 0.30 & 0.21 & 0.03 \\
\hline & & & & & \multicolumn{2}{|c|}{ Mean error: } & 0.14 & 0.21 & 0.27 \\
\hline
\end{tabular}

Values are in $\mathrm{cm}$

Table 2. Means and standard deviations of three dimensional coordinates of reference points when the JACOBY point is taken as the original point

\begin{tabular}{|c|c|c|c|c|c|c|}
\hline & \multicolumn{2}{|c|}{$\mathrm{X}$} & \multicolumn{2}{|c|}{$\mathrm{Y}$} & \multicolumn{2}{|r|}{$\mathrm{Z}$} \\
\hline & Mean & S.D. & Mean & S.D. & Mean & S.D. \\
\hline Suprasternale & 0.95 & 1.68 & 12.27 & 2.74 & 36.11 & 2.31 \\
\hline Mesosternale & 0.61 & 1.61 & 15.44 & 2.49 & 26.89 & 2.13 \\
\hline Xiphiale & 0.28 & 1.66 & 16.78 & 2.36 & 18.46 & 2.32 \\
\hline Iliospinale & 12.52 & 2.04 & 15.26 & 1.78 & -6.70 & 1.88 \\
\hline Subscapular point & 9.45 & 1.73 & -4.44 & 1.92 & 24.11 & 2.51 \\
\hline Cervicale & 0.48 & 1.39 & 1.11 & 2.41 & 42.88 & 2.34 \\
\hline Spinous process of $\mathrm{T} 4$ & 0.05 & 1.29 & -2.93 & 2.33 & 33.95 & 2.41 \\
\hline Spinous process of $\mathrm{T} 8$ & -0.18 & 1.01 & -3.85 & 1.96 & 23.04 & 2.46 \\
\hline Spinous process of $\mathrm{T} 12$ & 0.22 & 0.98 & -1.81 & 1.41 & 12.60 & 2.55 \\
\hline JACOBY point & 0.00 & 0.00 & 0.00 & 0.00 & 0.00 & 0.00 \\
\hline Acromiale & 19.77 & 1.70 & 5.40 & 2.46 & 36.15 & 2.66 \\
\hline Midlateral point of thorax & 14.82 & 2.02 & 7.82 & 2.35 & 19.73 & 2.36 \\
\hline Iliocristale & 14.15 & 1.83 & 8.42 & 1.66 & -0.47 & 1.61 \\
\hline
\end{tabular}

Values are in $\mathrm{cm}$ 


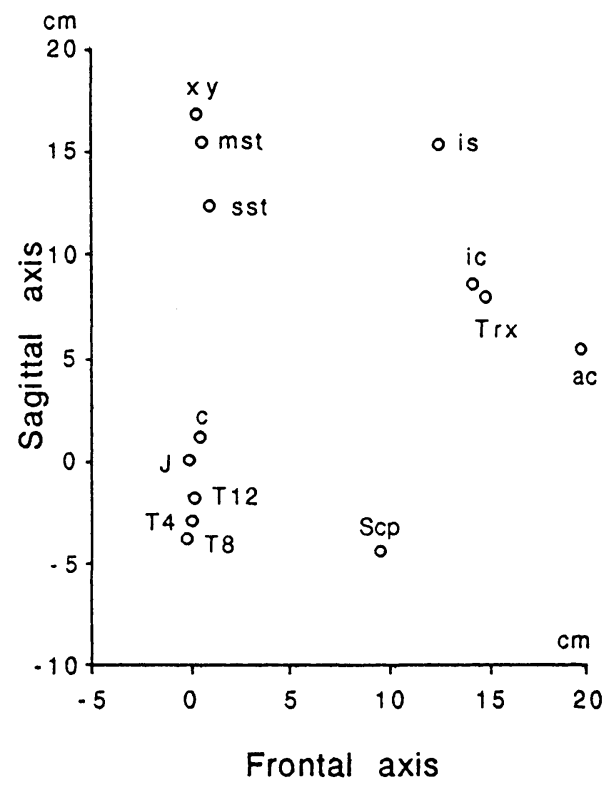

Fig. 2. Distribution of the reference points projected onto horizontal plane. For abbreviations of landmarks, see text.

precise on a theoretical basis but this method does not compensate for the human errors that accompany the ordinary measurement process of anthropometry. Examiners may produce errors when they detect the anatomical points and put the marks in place. Another possibility of error is in the process of data input by digitizer when using the video image analyzer. This error would be reduced if the data were acquired from $35 \mathrm{~mm}$ film. Two benefits of video are ease of manipulation and it is more economical. However, the error factor by video analysis is not so serious, as shown in Table 1. Therefore, overall accuracy of this method may be close to ordinary anthropometry with traditional anthropometers. The eight points along the midsagittal line of the body are not necessarily arrayed in a straight line (Fig. 2-4). This may be caused by the technical error in addition to the asymmetrical alignment of the reference points on human body.

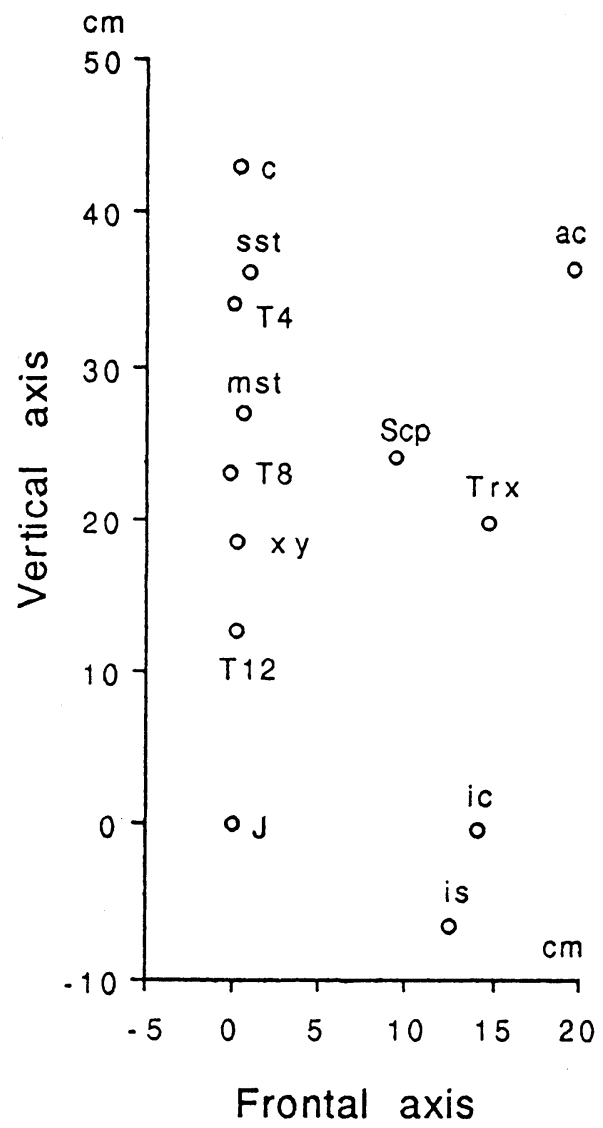

Fig. 3. Distribution of the reference points projected onto frontal plane.

Peculiar advantages of the DLT method as an anthropometric tool derive from its indirect computation method. The three dimensional coordinates of the reference points can produce any kind of linear and angular dimensions required. This may match the various diverse requests for the application of anthropometric data. Another advantage of this method is that it is non-invasive except for the process of detecting the reference points of the body. Testing time is also very short. Once the DLT parameters are acquired, the analytical process is not complicated provided the test is done using the same conditions. 


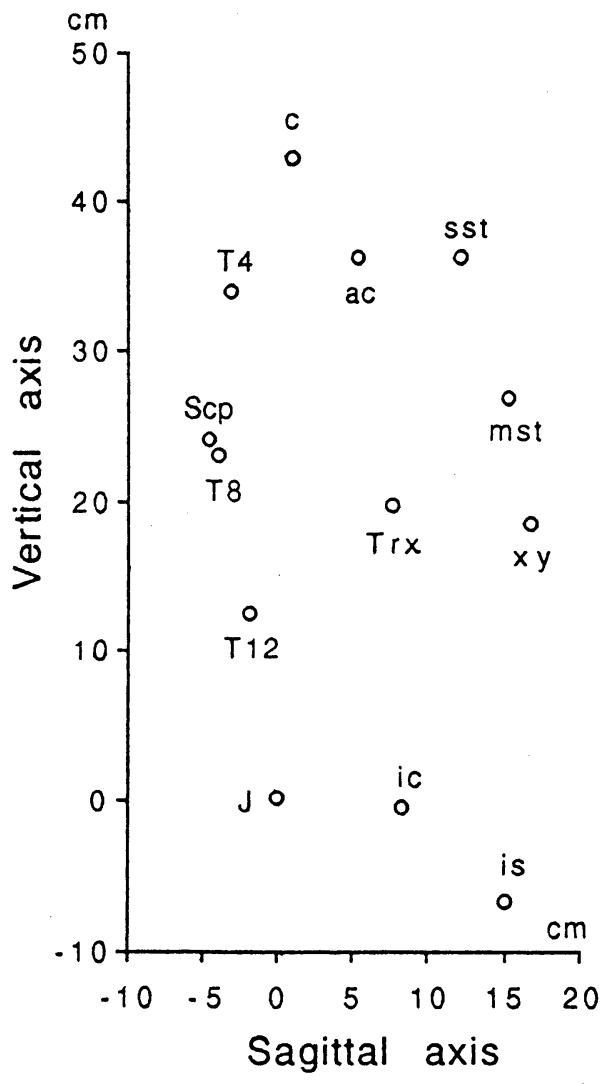

Fig. 4. Distribution of the reference points projected onto sagittal plane.

If we must find some disadvantages with this method, it does require sufficient space to set cameras surrounding the subject and maintain conditions while the tests are conducted. Some parts of the body are difficult to detect by surrounding cameras when the subject is in a normal standing posture. However, masked body parts could be revealed by minimum postural modifications such as the abduction of the upper limbs.

Although there are some limits to application, the DLT method will develop as a useful anthropometric tool.
Table 3. Means and standard deviations of linear dimensions between two reference points

\begin{tabular}{lrr}
\hline & Mean & S.D. \\
\hline Sst - mst & 9.8 & 1.07 \\
Mst - xy & 8.6 & 1.09 \\
Sst - xy & 18.3 & 1.72 \\
Sst - ac & 20.2 & 1.73 \\
Sst - C7 & 13.3 & 1.35 \\
Xy - T12 & 19.8 & 1.83 \\
Mst - Trx & 17.9 & 1.77 \\
Ic - J & 16.6 & 1.81 \\
Ic - is & 9.8 & 1.80 \\
Ic - Trx & 20.3 & 2.04 \\
Trx - T8 & 19.6 & 1.65 \\
Trx - ac & 17.5 & 2.18 \\
Scp - Trx & 14.4 & 1.61 \\
Scp - T8 & 10.0 & 1.39 \\
C7 - T4 & 9.9 & 1.25 \\
T4 - T8 & 11.0 & 1.40 \\
T8 - T12 & 10.8 & 13.6 \\
T12 - J & 12.8 & 2.59 \\
C7 - J & 43.0 & 2.36 \\
\hline
\end{tabular}

Values are in $\mathrm{cm}$

Table 4. Means and standard deviations of angular measurements (degree)

\begin{tabular}{lrr}
\hline & Mean & \multicolumn{1}{c}{ SD } \\
\hline Sst-mst-xy & 168.44 & 6.25 \\
Sst-ac-c & 37.34 & 4.50 \\
C-T4-T8 & 159.17 & 6.69 \\
T4-T8-T12 & 162.28 & 6.80 \\
T8-T12-J & 169.72 & 5.61 \\
Is-ic-J & 103.24 & 12.03 \\
Ac-Trx-ic & 161.62 & 6.33 \\
\hline
\end{tabular}


抄

録

D L T法による生体計測

服部恒明

披験者の周囲に配置した 4 台のビデオカメラによ り同期撮影した映像によって，体幹部の三次元座標 をDLT法によって求めた. D L T法によって得た 座標値と実座標の誤差は $\mathrm{x}, \mathrm{y}, \mathrm{z}$ ，座標とも $1 \%$ 未 満であった，座標值を用いて座標点を結ぶ任意の径 や角度を算出することができ，生体計測法のひとつ として有効であると結論された.

\section{References}

ASHIZAWA, K., K. KUKI and A. KATSUMOTO, 1985: Fringe patterns and measurement on dorsal moiré topography in Japanese children, aged 13 and 14. Am. J. Phys. Anthropol., 68: 359-369.

HATTORI, K. and F. NISHIO, 1982: Diurnal change of the relief on the body back surface. Jpn. J. Hum. Posture, 2: 73-78. (In Japanese with English summary)

HATZE, H., 1988: High-precision three-dimensional photogrammetric calibration and object space reconstraction using a modified DLT-approach. J. Biomechanics, 21: 533-538.

SHAPIRO, R., 1978: Direct linear transformation method for three-dimensional cinematography. Res. Quart., 49: 197-205.

WALTON, J.S., 1979: Close-range cine-photogrammetry: Another approach to motion analysis. In: Biomechanics Cinematography, Academic Publishers, pp.69-97.

\section{服部 恒 明茨城大学教養部身体活動科学研究室}

厂310 水戸市文京 2-1-1

Komei HATTORI Laboratory of Anatomy and Physical Activity Sciences, College of General Education, Ibaraki University

2-1-1 Bunkyo, Mito 310, Japan 